\author{
Sofiya BURCHENYA ${ }^{1}$ \\ Ivan DOBRYANSKYY ${ }^{2}$ \\ Yuriy FAMULYAK ${ }^{3}$ \\ Justyna SOBCZAK-PIĄSTKA ${ }^{4}$
}

\title{
BADANIE NOŚNOŚCI BELEK ŻELBETOWYCH DOZBROJONYCH STALOWYMI SIATKAMI CIĘTO-CIĄGNIONYMI
}

\begin{abstract}
W artykule przedstawiono wyniki badań nośności oraz momentu pojawienia się pęknięć i odkształceń konstrukcji żelbetowych zginanych belek ze wzmocnieniem zewnętrznym w formie stalowej siatki cięto-ciągnionej. Rozpatrzono przypadek umieszczenia siatki bez warstwy ochronnej $\mathrm{z}$ betonu oraz $\mathrm{z}$ warstwą ochronną w postaci betonu (otuliny). We wcześniejszych badaniach eksperymentalnie potwierdzono, że siatka cięto-ciągniona zapewnia bardziej niezawodną sczepność $\mathrm{z}$ powierzchnią betonu, niż beton $\mathrm{z}$ arkuszem blachy falistej lub gładkiej i systemem dospawanych kotew.
\end{abstract}

Słowa kluczowe: nośność, stalowa siatka cięto-ciągniona, odkształcenia, zginane konstrukcje belkowe, wzmocnienie zewnętrzne

\section{Wprowadzenie}

W 1967 roku na Wydziale Konstrukcji Budowlanych Lwowskiego Narodowego Uniwersytetu Rolniczego rozpoczęto badania konstrukcji żelbetowych, wzmocnionych zewnętrznym zbrojeniem pasmowym. Założycielem Lwowskiej szkoły naukowej konstrukcji żelbetowych z zewnętrznym zbrojeniem pasmowym był Ph.D. Profesor F.Ye.Klymenko [2]. Obecnie pod kierunkiem Dr HC Profesora I.M. Dobriańskiego we Lwowskim Narodowym Uniwersytecie Rolniczym przeprowadza się nadal badania takich konstrukcji [1].

\footnotetext{
${ }^{1}$ Autor do korespondencji/corresponding author: Sofiya Burchenya, Wydział Budownictwa i Architektury, Lwowski Narodowy Uniwersytet Rolniczy, e-mail: yufam@ukr.net

2 Ivan Dobryanskyy, Wydział Budownictwa i Architektury, Lwowski Narodowy Uniwersytet Rolniczy, e-mail: yufam@ukr.net

${ }^{3}$ Yuriy Famulyak, Wydział Budownictwa i Architektury, Lwowski Narodowy Uniwersytet Rolniczy, e-mail: yufam@ukr.net

${ }^{4}$ Justyna Sobczak-Piąstka, Wydział Budownictwa, Architektury i Inżynierii Środowiska, Uniwersytet Technologiczno-Przyrodniczy im. Jana i Jędrzeja Śniadeckich w Bydgoszczy
} 
W rozwój i badania konstrukcji betonowych zaangażowane są także inne zespoły prowadzone przez wybitnych naukowców i badaczy z Ukrainy: O.B. Golysheva, V.I. Efimenka, L.I. Storozhenka, O.V. Semka, E. Chykhladze, O.L. Shagina i innych [7]. Do tworzenia żelbetowych konstrukcji belkowych z zewnętrznym zbrojeniem pasmowym wyżej wymienieni naukowcy zwykle stosowali zbrojenia z prętów gładkich i żebrowanych, płaskiej blachy lub falistej blachy dachowej.

Ogólnie wiadomo, że przy zginaniu elementów dostrzegamy znaczną koncentrację naprężeń w punktach połączeń pasma zbrojenia z betonem. Siły adhezji i tarcia, które powstają w płaszczyźnie styku betonu i gładkich prętów zbrojeniowych lub płaskiego arkusza blachy są niewielkie. Współpracę zbrojonego żelbetowego przekroju zapewnia się więc przez zastosowanie jednostronnej chropowatości płaskiej blachy, użycie różnych łączników, np. elastycznych i sztywnych kotew, przestrzennych pionowych lub ukośnych prętów (rys. 1). Montowanie dodatkowych elementów kotwiących zapewnia dobrą współpracę zbrojenia i betonu, a to w znaczący sposób wpływa na zwiększenie nośności. Wzmocnienie to wymaga jednak dodatkowych operacji technologicznych, powstaje też niepożądana koncentracja naprężeń $[3,8]$.

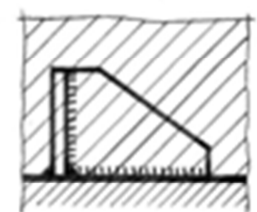

a)

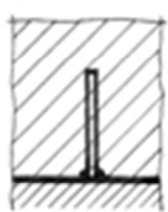

b)

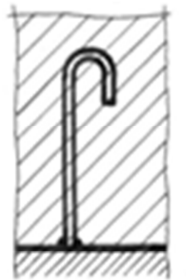

c)

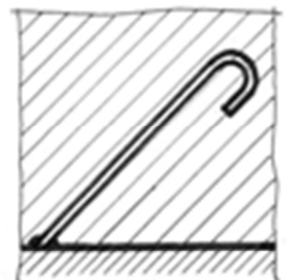

d)

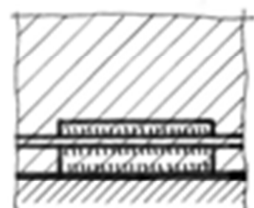

e)

Rys. 1. Rodzaje łączników: a - podpora sztywna; b - podpora elastyczna; c - kotew pionowa; $\mathrm{d}$ - kotew pochylona; e - wzmocnienie wzdłużne, przyspawane do blach

Fig. 1. Types of connectors: $a$ - stiff mainstay; $b$ - elastic mainstay; $c$ - vertical anchors; $d$ - slanting anchors; $\mathrm{e}-$ longitudinal reinforcement, welded to the sheet metal

We współczesnej praktyce budowlanej powszechnie stosowany jest typ wzmocnienia pasmowego - stalowa siatka cięto-ciągniona (SSCC). Ze względu na oryginalny kształt geometryczny powierzchni bocznej i dobre właściwości wytrzymałościowe, SSCC może być stosowana jako wzmocnienie zewnętrzne klasycznego zbrojenia betonu z prętów, zarówno dla struktur belkowych, jak i płytowych. W pracy zostanie przedstawiony przypadek zastosowania siatki cięto-ciągnionej do zbrojenia belki zginanej. 


\section{Sformułowanie problemu}

Siatki cięto-ciągnione SSCC wykonane są ze zwykłego arkusza blachy metalowej. Proces produkcji siatki polega na nacinaniu i jednoczesnym rozciąganiu blachy, co zmniejsza jej masę, ale pozwala przy tym zachować wskaźniki jakościowe i ilościowe potrzebne do utrzymania nośności i sztywności. SSCC jest o 80\% lżejsza niż lite blachy o podobnych wymiarach i grubości. W celu zmniejszenia potencjalnego odkształcania arkusza jest on walcowany, a więc arkusz siatki jest bardziej płaski, ale zwiększa się przy tym jego odporność na odkształcenia [6].

Siatki mają z jednej strony teksturę płaską z drugiej chropowatą, co zapobiega poślizgowi na powierzchni SSCC. Charakteryzują się także większą wydajnością eksploatacyjną $\mathrm{w}$ stosunku do pełnych arkuszy blach i znacząco zmniejszają koszt użytej do ich produkcji stali. Wymienione cechy siatki ciętociągnionej SSCC sprawiają, że coraz częściej jest ona wykorzystywana do zbrojenia betonu, ale także plastiku i innych tworzyw sztucznych. Ten rodzaj zbrojenia gwarantuje dobrą sczepność z betonem zbrojonym klasycznymi prętami, bez żadnych dodatkowych elementów łączących.

Celem przestawionego badania była analiza nośności i odkształcalności konstrukcji belek zbrojonych stalową siatką cięto-ciągnioną z ochronną warstwą betonu i bez otuliny.

\section{Przedstawienie wyników badań i analiz}

Do badania pracy belek wzmocnionych stalową siatką cięto-ciągnioną wykonano prototypy z betonu klasy C35/45. Zbrojenie belek wykonano z prętów zbrojeniowych klasy A240S. W belkach oznaczonych symbolami B-II-1 i B-II-1* (rys. 2a) wykonano dodatkowe zbrojenie $\mathrm{z}$ siatki cięto-ciągnionej osłoniętej warstwą ochronną z betonu (rys. 2a). Natomiast w belkach oznaczonych symbolami B-II-2 i B-II-2* (rys 2b) wykonano dodatkowe zbrojenie z siatki cięto-ciągnionej bez warstwy ochronnej z betonu. Przekrój poprzeczny belek ma wymiar $135 \times 270$ $\mathrm{mm}$, całkowita długość belki wynosi $2300 \mathrm{~mm}$, natomiast rozpiętość obliczeniowa - $2000 \mathrm{~mm}$ (belki z gwiazdką ${ }^{*}$-są to tzw. belki odpowiedniki) [4, 5].

Charakterystyki siatki SSCC, która służyła jako wzmocnienie zewnętrzne w prototypach belki były następujące: marka CC 408 zgodnie ze specyfikacjami normy 27.1-13625948-002: 2006, grubość elementu $t=4 \mathrm{~mm}$, szerokość tzw. mostka powstałego $\mathrm{w}$ procesie nacinania i rozciągania $B=8 \mathrm{~mm}$, całkowity wymiar komórki $C=90 \mathrm{~mm}$, krótsza przekątna oczka mierzona w tzw. węzłach $h=25 \mathrm{~mm}$, całkowita grubość arkusza po rozciągnięciu $S=16 \mathrm{~mm}$, wielkość tzw. wyciągu $A=12,5 \mathrm{~mm}$ (rys. 4). Schematy wzmocnienia prototypów belek przez siatki SSCC pokazano na rysunkach 2-3.

Przed przeprowadzeniem badań eksperymentalnych, określono podstawowe właściwości fizyczne i mechaniczne prętów zbrojeniowych, siatek SSCC oraz betonu. Wyniki testów i obliczeń przedstawiono w tabeli 1-2. 


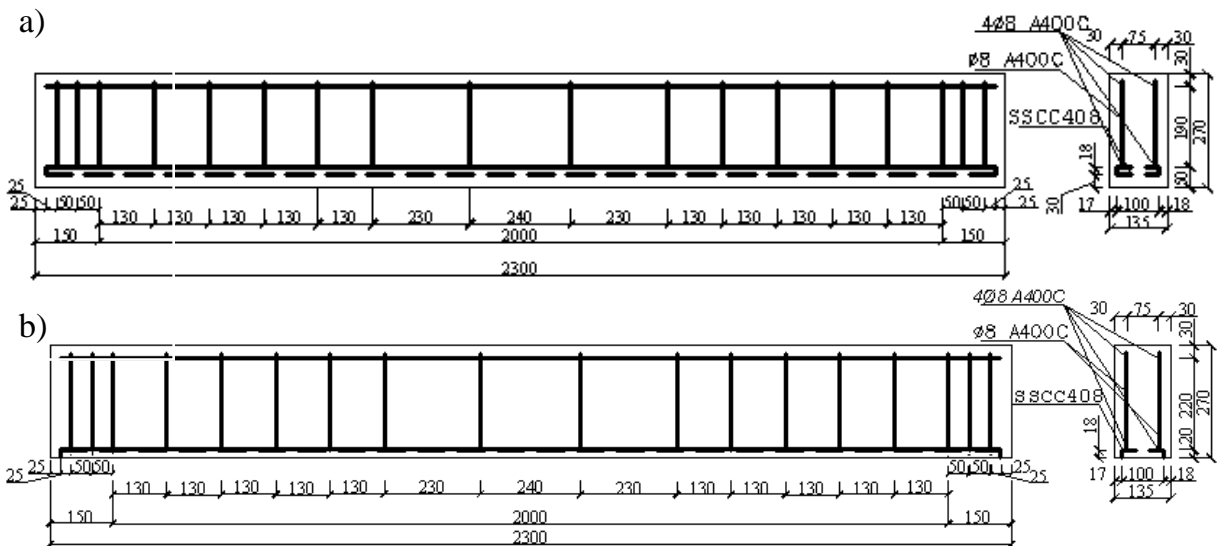

Rys. 2. Schemat prototypów belek zbrojonych siatką cięto-ciągnioną

a) $\mathrm{z}$ otuliną betonową B-II-1, B-II-1*; b) bez otuliny betonowej B-II-2, B-II-2*

Fig. 2. Diagram of prototypes of reinforced beams with the cut and stretchy sheet

a) with a layer of concrete B-II-1, B-II- *; $^{\text {; }}$ ) without a layer of concrete B-II-2, B-II-2*

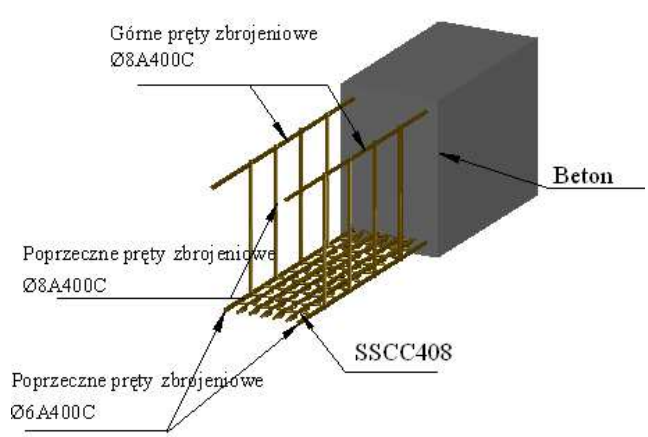

Rys. 3. Konstrukcja prototypu

Fig. 3. The construction of the prototype

Tabela 1. Wartości określające właściwości stali

Table 1 . The values describing of steel properties

\begin{tabular}{|c|c|c|c|c|c|}
\hline $\begin{array}{c}\text { Rodzaje } \\
\text { wzmocnień }\end{array}$ & $\begin{array}{c}\text { Wymiary } \\
\text { przekroju } \\
\text { poprzecznego } \\
\text { średnica } \\
{[\mathrm{mm}]}\end{array}$ & $\begin{array}{c}\text { Pole przekroju } \\
\text { poprzecznego } \\
\mathrm{A}\left[\mathrm{cm}^{2}\right]\end{array}$ & $\begin{array}{c}\text { Obliczeniowa } \\
\text { wartość wytrzy- } \\
\text { małości zbrojenia } \\
f_{y k}[\mathrm{MPa}]\end{array}$ & $\begin{array}{c}\text { Moduł spręży- } \\
\text { stości podłużej } \\
\text { zbrojenia } \\
E_{s} \times 10^{5}[\mathrm{MPa}]\end{array}$ & $\begin{array}{c}\text { Dopuszczalne } \\
\text { względne od- } \\
\text { kształcenia } \\
\text { przy rozciąganiu } \\
\mathcal{E}_{u d}\end{array}$ \\
\hline \hline SSCC & $50 \mathrm{x} 4$ & 1,12 & 271 & 2,05 & 0,025 \\
\hline $\begin{array}{c}\text { Pręt klasy } \\
\text { A240S }\end{array}$ & $\varnothing 6$ & 0,283 & 316 & 2,01 & 0,023 \\
\hline $\begin{array}{c}\text { Pręt klasy } \\
\text { A400S }\end{array}$ & $\varnothing 8$ & 0,503 & 600 & 1,96 & - \\
\hline
\end{tabular}

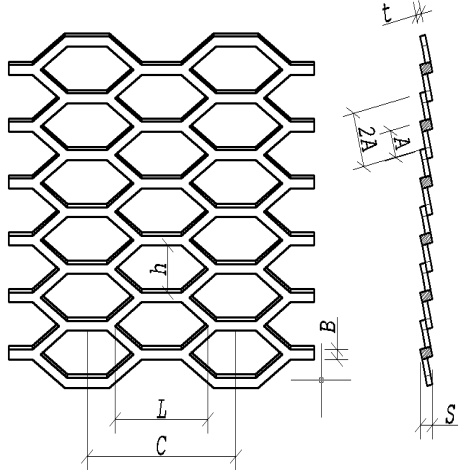

Rys. 4. Parametry SSCC

Fig. 4. Parameters of SSCC 
Tabela 2. Podstawowe właściwości fizyczne i mechaniczne betonu po 28 dniach

Table 2. Basic physical and mechanical properties of concrete after 28 days

\begin{tabular}{|c|c|c|c|}
\hline \multirow[b]{2}{*}{$\begin{array}{l}\text { Oznaczenie } \\
\text { belki }\end{array}$} & \multirow{2}{*}{$\begin{array}{c}\text { Wytrzymałość beto- } \\
\text { nu na ściskanie bada- } \\
\text { na na kostkach sze- } \\
\text { ściennych } \\
f_{c d, c u b e} \\
{[M P a]}\end{array}$} & \multirow{2}{*}{$\begin{array}{c}\text { Obliczeniowa wytrzyma- } \\
\text { łość betonu na ściskanie } \\
\text { po } 28 \text { dniach (wytrzyma- } \\
\text { łość badana na próbkach } \\
\text { walcowych) } \\
f_{c d, p r i s m} \\
{[M P a]}\end{array}$} & $\begin{array}{c}\text { Moduł sprężystości } \\
E_{c d} \\
{[M P a]}\end{array}$ \\
\hline & & & $\begin{array}{c}\text { Na podstawie wyników uzyska- } \\
\text { nych na próbkach o wymiarach } \\
150 \times 150 \times 600 \\
{[\mathrm{~mm}]}\end{array}$ \\
\hline B-II-1 & \multirow{4}{*}{39,3} & \multirow{4}{*}{32,6} & \multirow{4}{*}{33840} \\
\hline B-II-1* & & & \\
\hline B-II-2 & & & \\
\hline B-II-2* & & & \\
\hline
\end{tabular}

Badania żelbetowych belek wzmocnionych SSCC przeprowadzone były na specjalnym stanowisku. Zastosowano obciążenie w postaci dwóch symetrycznie działających sił skupionych przyłożonych do górnej powierzchni belek (rys. 5).

Wzrost obciążenia odbywał się stopniowo co $0,05 \div 0,1 \mathrm{kN}$, aż do obciążenia niszczącego, przy czym przerwa pomiędzy kolejnymi wzrostami obciążenia wynosiła 25-30 minut. W procesie obciążania prototypów belek, po każdym etapie dociążania notowane były wskazania tensometrów przy pomocy automatycznego elektronicznego miernika odkształcenia AID-4, który rejestrował deformacje odczytywane z mikroczujników (tensometrów), przymocowanych do powierzchni prototypu belki. Przemieszczenie belek mierzone było przy pomocy

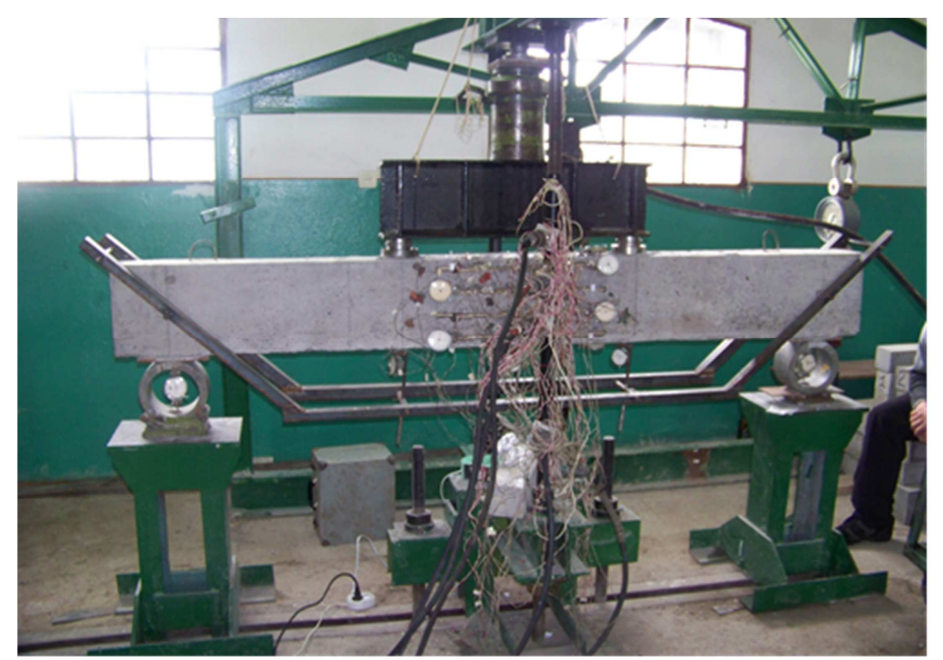

Rys. 5. Widok ogólny stanowiska badawczego

Fig. 5. General view of the testing stand 
czujników ze wskaźnikami o wartości nominalnej wynoszącej 0,01 $\mathrm{mm}$. Wskaźniki te były umieszczone w środku belki oraz na osi działania sił zewnętrznych (rys. 5). Jednocześnie obserwowano powierzchnię boczną belki i rejestrowano pojawienie się i rozwój pęknięć w betonie (w tym wysokość i szerokość szczeliny). Rozwój i rozwarcie pęknięć obserwowano przy wykorzystaniu mikroskopu pomiarowego MPB-2M.

W belkach prototypowych B-II-1, B-II-1* pierwsze pęknięcia zaobserwowano przy obciążeniu powodującym powstanie momentu zginającego o wartości odpowiednio $M_{c r c}{ }^{e x p}=793 \mathrm{kNcm}$ dla próbki B-II-1 oraz $M_{c r c}{ }^{e x p}=665,27 \mathrm{kNcm}$ dla próbki B-II-1*. W próbkach B-II-2, B-II-2* pierwsze pęknięcia zaobserwowano przy obciążeniu powodującym powstanie momentu zginającego o wartości odpowiednio $M_{c r c}{ }^{e x p}=845 \mathrm{kNcm}$ dla próbki B-II-2 oraz $M_{c r c}{ }^{\text {exp }}=855,40 \mathrm{kNcm}$ dla próbki B-II-2*. Można więc zauważyć, że pęknięcia w belkach B-II-2, B-II2* pojawiły się później niż w próbkach B-II-1, B-II-1* (o około 1,07-1,28 raza).

Ustalenie stanu granicznego nośności belek prototypowych zostało przeprowadzone przy wykorzystaniu uzyskanych wcześniej wyników badań laboratoryjnych odkształcenia siatek SSCC i prętów zbrojeniowych podczas próby rozciągania. Podczas badań laboratoryjnych belek prototypowych zbrojonych siatkami cięto-ciągnionymi SSCC, ustalono wartości doświadczalne obciążeń i odpowiadające im wartości doświadczalne momentów zginających, przy których występowało przekroczenie w zbrojeniu granicy plastyczności (plastyczne płynięcie stali), a następnie zniszczenie strefy ściskanej betonu (tabela 3). Okazało się, że w momencie osiągnięcia przez stalowe siatki SSCC granicy plastyczności (plastyczne płynięcie stali), wytrzymałość betonu w strefie ściskanej belek prototypowych była wykorzystana na poziomie $35-40 \%$.

W celu dokładniejszego określenia odkształcenia betonu w ściskanych i rozciąganych obszarach oraz ugięć, przyjęto $\mathrm{w}$ dalszych analizach wartość momentu zginającego, która jest równa $0,83-0,85 M_{t}$. Moment $M_{t}$ jest wartością wyliczonego momentu zginającego $\mathrm{w}$ belkach prototypowych zbrojonych siatkami cięto - ciągnionymi SSCC, odpowiadającego osiągnięciu przez to zbrojenie granicy plastyczności. Wartości te zestawiono w tabeli 4.

Tabela 3. Graniczne wartości doświadczalne i niszczące momenty zginające

Table 3. The limit experimental values and destructive bending moments

\begin{tabular}{|c|c|c|c|c|}
\hline $\begin{array}{c}\text { Oznaczenie } \\
\text { belki }\end{array}$ & $\begin{array}{c}\text { Doświadczalny } \\
\text { graniczny mo- } \\
\text { ment zginający } \\
\mathrm{M}, \mathrm{kNcm}\end{array}$ & $\begin{array}{c}\text { Wysokość } \\
\text { strefy ściska- } \\
\text { nej betonu } \\
\mathrm{cm}\end{array}$ & $\begin{array}{c}\text { Wykorzystanie wy- } \\
\text { trzymałości betonu na } \\
\text { początku plastycznego } \\
\text { płynięcia zbrojenia } \\
\%\end{array}$ & $\begin{array}{c}\text { Doświadczalny } \\
\text { moment nisz- } \\
\text { czący } \\
\mathrm{M}_{\text {eks }}^{\text {nisz }}, \mathrm{kNcm}\end{array}$ \\
\hline \hline B-II-1* & 1202,5 & 6,43 & 35 & 1527,50 \\
\hline B-II-1 & 1202,5 & 6,43 & 35 & 1540,50 \\
\hline B-II-2 & 1365,0 & 7,40 & 39,4 & 1690,00 \\
\hline B-II-2* & 1365,0 & 7,40 & 39,4 & 1678,62 \\
\hline
\end{tabular}


Tabela 4. Wartości eksperymentalne

Table 4. Experimental values

\begin{tabular}{|c|c|c|c|c|c|}
\hline $\begin{array}{l}\text { Oznaczenie } \\
\text { belki }\end{array}$ & $\begin{array}{c}\text { Moment zgina- } \\
\text { jący, który } \\
\text { odpowiada } \\
0,83-0,85 \\
M_{t}^{S S C C} \\
\mathrm{kN}^{*} \mathrm{~cm} \\
\end{array}$ & $\begin{array}{c}\text { Zmierzone } \\
\text { ugięcie } \\
f^{\exp }, \\
m m\end{array}$ & $\begin{array}{l}\text { Odkształcenia w } \\
\text { skrajnych rozcią- } \\
\text { ganych włóknach } \\
\text { betonu } \\
\mathcal{E}_{\exp _{\mathrm{c}(2)}} \times 10^{-5}\end{array}$ & $\begin{array}{c}\text { Odkształcenia w } \\
\text { skrajnych ściska- } \\
\text { nych włóknach } \\
\text { betonu } \mathcal{E}_{\exp } \\
\times 10^{-5}\end{array}$ & $\begin{array}{c}\text { Odkształcenia na } \\
\text { poziomie rozcią- } \\
\text { ganego zbrojenia } \\
\mathcal{E} \exp _{\mathrm{s}} \times \\
10^{-5}\end{array}$ \\
\hline B-II-1* & 1140,75 & 1,87 & $-139,6$ & 46,5 & $-108,1$ \\
\hline B-II-1 & 1140,75 & 1,89 & $-135,2$ & 45,5 & $-106,3$ \\
\hline B-II-2 & 1140,8 & 1,93 & $-100,2$ & 32,5 & $-78,6$ \\
\hline B-II-2* & 1140,8 & 1,90 & $-99,0$ & 33,4 & $-79,0$ \\
\hline
\end{tabular}

W tabeli 4. pokazano, że w próbkach eksperymentalnych B-II-2, B-II-2* (wzmocnionych SSCC bez warstwy ochronnej) odkształcenia graniczne w strefie rozciąganej betek prototypowych są o 1,4 razy mniejsze w porównaniu z belkami B-II-1, B-II-1*. Deformacja graniczna ściskanych włókien w belce B-II-2 jest o 1,36 razy mniejsza w porównaniu z badaną belką B-II-1.

W celu lepszego oszacowania nośności belki wzmocnionej SSCC bez warstwy ochronnej (B-II-1, B-II-1*) oraz z warstwą ochronną z betonu (B-II-2, B II$2^{*}$ ) zestawiono zależności ugięcia od obciążenia rys.6.

$\mathrm{Na}$ rysunku 6. przedstawiono wartości ugięć belki prototypowej B-II-1 (zbrojona siatką SSCC z warstwą ochronną) i B-II-2 (zbrojona siatką SSCC bez warstwy ochronnej). Do poziomu obciążenia odpowiadającego momentowi około $1000 \mathrm{kNcm}$ są one niemal identyczne, a w dalszej części wykresu nadal różnią się nieznacznie. Przy obciążeniu, które jest zbliżone do wartości niszczącej, wartość ugięcia jest niemal identyczna dla belki prototypowej B-II- $2-f_{\text {exp }}=3,7 \mathrm{~mm}$ i dla belki prototypowej B-II- $1-f_{\text {exp }}=3,52 \mathrm{~mm}$.

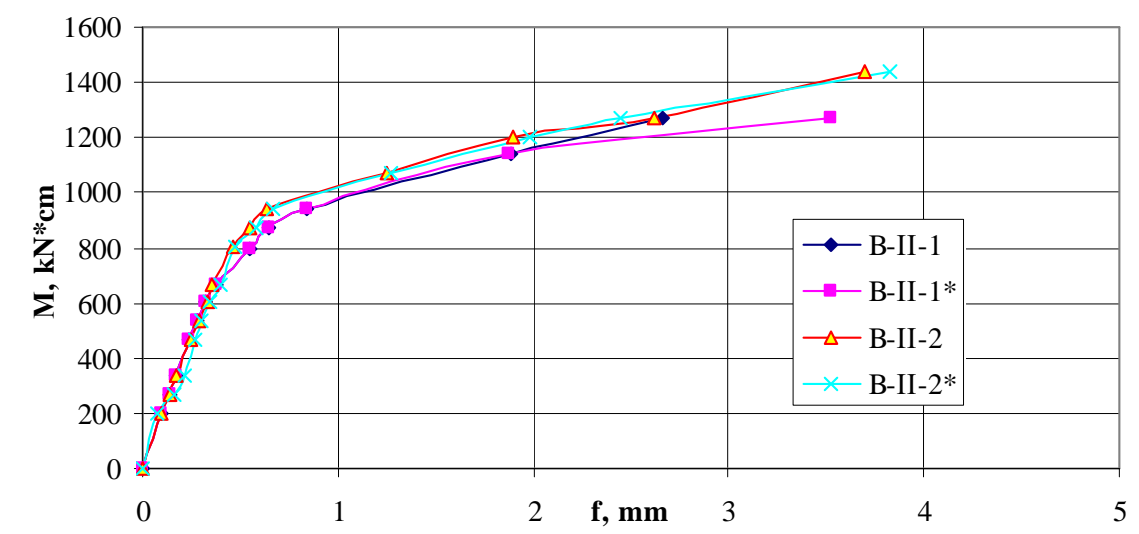

Rys. 6. Zależność eksperymentalnych ugięć belek B-II-1, B-II-1* oraz B-II-2, B-II-2* od poziomu obciążenia Fig. 6. Dependence of the experimental beams deflections B-II-1, B-II-1* and B-II-2, B-II- $2 *$ of the load level 
Wszystkie badane belki prototypowe obciążane były do całkowitego ich fizycznego zniszczenia. Charakter pękania poszczególnych belek pokazano przykładowo na rys. 7.

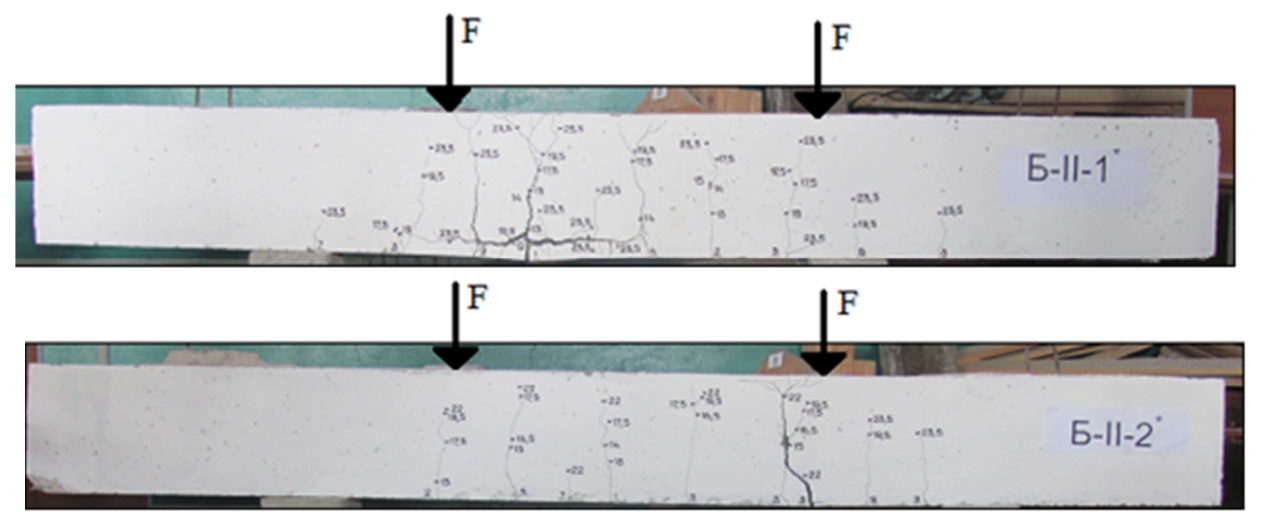

Rys. 7. Charakter zniszczenia belek

Fig. 7. The nature of the destruction of beams

\section{Wnioski}

1. Przeprowadzone badania eksperymentalne potwierdziły, że stalowa siatka cięto-ciągniona zapewnia niezawodną sczepność z warstwą betonu. Porównania wykonywano $\mathrm{z}$ analogicznym arkuszem blachy falistej lub gładkiej z systemem spawanych kotew.

2. Stwierdzono, że ustalona doświadczalnie wartość momentu zginającego w chwili pojawienia się pierwszych zarysowań w badanych belkach prototypowych wzmocnionych SSCC bez warstwy ochronnej betonowej jest o 1,07-1,28 razy wyższy, niż w podobnych prototypach z warstwą ochronną.

3. Nośność belek wzmocnionych SSCC bez warstwy ochronnej betonu jest większa o 1,09-1,21 razy w porównaniu z belką wzmocnioną SSCC z warstwą ochronną, poprzez zwiększenie wewnętrznego ramienia pary sił.

4. Potwierdzono eksperymentalnie, że przy tej samej wartości obciążenia, odkształcenie belek, gdzie SSCC jest bez warstwy ochronnej z betonu, jest mniejsze o 1,13 razy, w porównaniu z taką samą belką wzmocnioną SSCC, ale $\mathrm{z}$ warstwą ochronną $\mathrm{z}$ betonu.

5. Wartości ugięć dla belki wzmocnionej SSCC bez warstwy ochronnej z betonu i dla belki wzmocnionej SSCC $\mathrm{z}$ warstwą ochronną z betonu były porównywalne.

6. Planuje się wykonanie dalszych badań, w których będą stosowane innego typu siatki cięto-ciągnione. Analizie będzie poddany także aspekt zabezpieczenia antykorozyjnego siatki w belkach bez warstwy ochronnej z betonu. 


\title{
Literatura
}

[1] Добрянський І.: Експериментальне дослідження міцності нормальних перерізів згинаних балкових елементів, армованих просічно-витяжним листом // I. Добрянський, С. Бурченя, I. Шмиг // Теоретичні основи і практичні аспекти використання ресурсоощадних технологій для підвищення ефективності агропромислового виробництва і розвитку сільських територій : матеріали Міжнар. наук.-практ. форуму, 18-21 вересня 2012 р. - Львів, 2012. - С. 552-558.

[2] Клименко Ф. Е.: Сталебетонные конструкции с внешним полосовым армированием / Ф. Е. Клименко. - К. : Будівельник, 1984. - 88 с.

[3] Шмиг Р., Добрянський І., Бурченя С., Нікіфоряк С.: Обгрунтування доцільності застосування сталевого просічно-витяжного листа як робочої арматури у залізобетонних балкових конструкціях. Вісник Львівського національного аграрного університету : архітектура і сільськогосподарське будівництво 2013. - № 14. - С. 89 -100.

[4] Патент на корисну модель, u2011 08765 МПК Е04C 5/02(2006.01). Сталебетонний елемент / Добрянський І.М., Шмиг Р.А., Бурченя С.П. ; заявн. і патентовласник Львівський нац. аграрн. унів. - № 69032, заявл. 12.07.2011 ; опубл. 25.04.2012., Бюл. №8.

[5] Патент на корисну модель, u2011 08771 МПК Е04C 5/02(2006.01). Сталебетонний елемент / Добрянський І.М., Шмиг Р.А., Бурченя С.П. ; заявн. і патентовласник Львівський нац. аграрн. унів. - № 69035, заявл. 12.07.2011 ; опубл. 25.04.2012.. Бюл. №8.

[6] Просічно-витяжний лист [Електронний ресурс]. - Режим доступу : http://www.acrossteel.ru/list_8.html \{dostęp 10.06.2016\}.

[7] Стороженко Л. И.; Сталежелезобетонные конструкции / Л.И. Стороженко, А. В. Семко, В. И. Ефименко. - К. : Четверта хвиля, 1997. - 160 с.

[8] Фамуляк Ю. С. Міцність сталебетонних балок з торцевими анкерами в зоні дії поперечних сил : монографія / Ю. Є. Фамуляк, Ф. Є. Клименко, В. М. Барабаш. - Львів : Львів. держ. аграр. ун-т, 2006. - 117 с.

\section{TESTING CAPACITY OF CONCRETE REINFORCED BEAMS AND EXTRA REINFORCEMENT OF CUT AND STRETCHY STEEL SHEET}

\begin{abstract}
S u m m a r y
The results of the bearing capacity, cracks formation moment and stress-strain behavior of the reinforced bending beam structures with the external reinforcement in the form of steel cut and stretchy sheet which is placed with and without the protective layer of concrete are presented in the article. It is experimentally confirmed that the cut and stretchy sheet provides better adhesion with an array of concrete than a similar solid corrugated sheet or flat sheet with a system of welded anchors.
\end{abstract}

Keywords: bearing capacity, steel cut and stretchy sheet, stress-strain behavior, bending beam structures, external reinforcement

Przestano do redakcji: 07.06.2016 $r$.

Przyjęto do druku: 30.06.2016 r.

DOI: $10.7862 / r b .2016 .28$ 